2019-06-29

High-efficiency gravel longshore

sediment transport and headland

bypassing over an extreme wave event

\author{
McCarroll, Jak
}

http://hdl.handle.net/10026.1/14614

10.1002/esp.4692

Earth Surface Processes and Landforms

Wiley

All content in PEARL is protected by copyright law. Author manuscripts are made available in accordance with publisher policies. Please cite only the published version using the details provided on the item record or document. In the absence of an open licence (e.g. Creative Commons), permissions for further reuse of content should be sought from the publisher or author. 


\title{
High-efficiency gravel longshore sediment transport and headland bypassing over an extreme wave event
}

\author{
R. J. McCarroll ${ }^{1}$, G. Masselink ${ }^{1}$, M. Wiggins ${ }^{1}$, T. Scott ${ }^{1}$, O. Billson ${ }^{1,2}$, D. C. Conley ${ }^{1}$, N. G. \\ Valiente ${ }^{1}$ \\ ${ }^{1}$ School of Biological and Marine Sciences, Plymouth University, Drake Circus, PL4 8AA, Plymouth, UK; ${ }^{2}$ School of \\ Geography and Planning, University of Liverpool, Brownlow Hill, Liverpool, UK \\ Corresponding author: R. Jak McCarroll (jak.mccarroll@plymouth.ac.uk)
}

This is the author's accepted manuscript. The final published version of this work (the version of record) is published by Wiley Online Library in Earth Surface Processes and Landforms on 29 June 2019, available at: https://doi.org/10.1002/esp.4692. This work is made available in accordance with the publisher's policies.

\section{Key points:}

- Complete sediment budget spanning multiple adjacent gravel embayments over an extreme (1-in-50 year) event.

- High-energy gravel transport rate determined to be at least a factor of 5 or more than predicted based on existing formulations.

- First measured rates of headland bypassing, found to be controlled by shoreline orientation and headland extent.

\begin{abstract}
Gravel beaches are common throughout the high latitudes, but few studies have examined gravel transport rates, in particular at high energy levels, and no studies have quantified gravel transport around headlands. Here, we present the first complete sediment budget, including supra-, inter- and subtidal regions of the beach, across multiple headland-separated gravel embayments, combined with hydrodynamic observations, over an extreme storm sequence, representing at least a 1:50 year event. Unprecedented erosion was observed ( $400 \mathrm{~m}^{3} / \mathrm{m},-6 \mathrm{~m}$ vertical), with alongshore flux of $2 \times 10^{5} \mathrm{~m}^{3}$, equivalent to annual rates. Total system volume change was determined to the depth of closure and then used to calculate alongshore flux rates. Alongshore wave power was obtained from a wave transformation model. For an open section of coastline we derive a transport coefficient ('CERC' formula) of $K_{H s}=0.255 \pm 0.05$, exceeding estimates in lower energy conditions by a factor of 5 or more. We apply this coefficient to rocky segments of the shoreline, determining rates of headland bypass from 0 to $31 \%$ of potential flux, controlled by headland extent and toe-depth. Our results support the hypothesis that gravel is transported more efficiently at higher energy levels and that a variable rate or threshold approach may be required. Complete coverage and varying morphology make this dataset uniquely suited to improving model predictions of gravel shoreline change.
\end{abstract}

Keywords: Storm response, embayed beach, reflective beach, sediment budget, beach morphodynamics. 
McCarroll et al. Author's version of ESPL article, published 29 June 2019.

\section{Introduction}

Reliable prediction of longshore sediment transport is a fundamental requirement for coastal engineering and management applications on open and embayed coastlines worldwide. Transport rate estimates are necessary when evaluating the impact of coastal structures on sediment budgets (Van Rijn, 2011), to predict rates of beach rotation (Harley et al., 2011) and to estimate the longevity of beach nourishments (Luijendijk et al., 2017). To fully determine sediment budgets, lateral flux of sediment through a littoral cell, which involves headland bypassing (Vieira da Silva, 2016), must also be understood. Estimated longshore transport and bypassing rates, in combination with an understanding of cross-shore processes (McCall et al., 2014), can be applied to predict future shoreline change and to determine the safe set-back distance for coastal infrastructure (Woodroffe et al., 2012).

Gravel beaches are common throughout the mid- to high-latitudes, and while well-established values exist in relation to transport of sand-sized sediment (Schoonees and Theron, 1993), observations of coarse-grained longshore transport are limited to only a handful of studies (Van Wellen et al., 2000; Van Rijn, 2014; Bergillos et al., 2017a,b). This is due to the difficulties in working on gravel beaches (Van Wellen, 2000) and a lack of field studies that combine hydrodynamic observations with sediment transport rates. Gravel beach transport differs from that on sandy beaches (Van Wellen et al., 2000; Buscombe and Masselink, 2006; Ruiz de Alegria-Arzaburu and Masselink, 2010) as coarse sediment is more difficult to transport; however, steep beachface gradients allow for wave breaking closer to shore with limited refraction, potentially enhancing transport.

Several formulae have been developed to predict gravel transport (e.g., Van Wellen et al., 2000; Tomasicchio et al., 2013; Van Rijn, 2014), but these are based on an extremely limited set of observations, collected under low energy field conditions or relying on laboratory experimentation. Reliable field observations of pure gravel transport under more energtic wave conditions are limited to two sites: Shoreham, UK (Chadwick, 1989; Bray et al., 1996) and Hurst Castle Spit, UK (Nicholls and Wright, 1991). Using the energy flux approach (CERC equation; USACE, 2002), the volume of sediment transported is the product of alongshore wave power $\left(P_{y}\right)$ and a transport coefficient $(K)$. Van Wellen et al. (2000), using the Shoreham and Hurst Castle data, determined a $K$-value for gravel at $30 \%$ of the rate on a sandy beach. This was heavily influenced by the high transport rates of Bray et al. (1996) (up to $50 \%$ of sand-rates), while the remaining studies observed values of $1-10 \%$ that of sand. This higher value for $K$ is rarely cited.

While transport rates on long, open stretches of coastline may be amenable to a simple function of sediment characteristics and wave power, transport on embayed and rocky coastlines is often impeded by headlands and limitations in sediment supply. Although there has been recent interest in headland bypassing on sandy beaches (Goodwin et al., 2013; George et al., 2015; Vieira da Silva, 2016, 2018; McCarroll et al., 2018), little effort has been applied to understanding bypassing of gravel. Presently there are no quantitative observations of gravel headland bypassing rates, and no method for estimating bypassing in gravel environments.

This study describes the most comprehensive observations to date of gravel transport over an extreme event sequence and across the extent of a multi-beach embayment. We seek to relate alongshore wave power to volume flux along the embayment with two objectives: (i) to determine a sediment transport rate coefficient for an open-coast zone where flux is unconstrained by hard morphology; and (ii) to identify zones where headlands and a lack of sediment supply result in constrained rates of flux, and then determine rates of bypass at specific headlands. 


\section{Study site}

Start Bay is located on the south coast of Devon, UK (Fig. 1a). The shoreline is $12 \mathrm{~km}$ long with multiple gravel beach-barrier sub-embayments. From south to north (Fig. 1C) these include: Hallsands (HS), Beesands (BS), Slapton Sands (SS), Forest Cove (FC) and Blackpool Sands (BS). Start Bay has been the subject of multiple research studies into gravel beach dynamics (Chadwick et al., 2005; Masselink et al., 2010, 2016; Ruiz de Alegria-Arzaburu and Masselink, 2010; Scott et al., 2016; Wiggins et al., 2019).

Sediment is fine gravel, with a mean grain size of $D_{50}=2$ to $10 \mathrm{~mm}$ (Chadwick et al., 2005). The beachface is steep ( $\tan \beta=0.125)$, with a transition to a low-gradient sandy bottom at the $10-\mathrm{m}$ depth contour Ordnance Data Newlyn (ODN; mean sea level is c. $0.3 \mathrm{~m}$ ODN). At the offshore extent of the embayment lies Skerries Bank (Fig. 1c), comprised of medium and shelly sand (Hails, 1975). Skerries is $-5 \mathrm{~m}$ ODN deep at the shallowest point, inducing breaking during large wave events.

Start Bay is impacted by a bi-modal wave climate (Fig. 1b), with a dominant component of southerly waves and less frequent easterly waves. Waves are generally low (mean $H_{s}=0.7 \mathrm{~m}$ ), but storms with $H_{s}>2.2 \mathrm{~m}$ (Wiggins et al., 2019) occur from southerly and easterly directions during the winter (DecMar). The tidal regime is meso-macro tidal with a neap (spring) tidal range of $1.8 \mathrm{~m}(4.3 \mathrm{~m})$. The system is closed to north and south, but bypassing is inferred to occur between sub-embayments (Wiggins et al., 2019). 

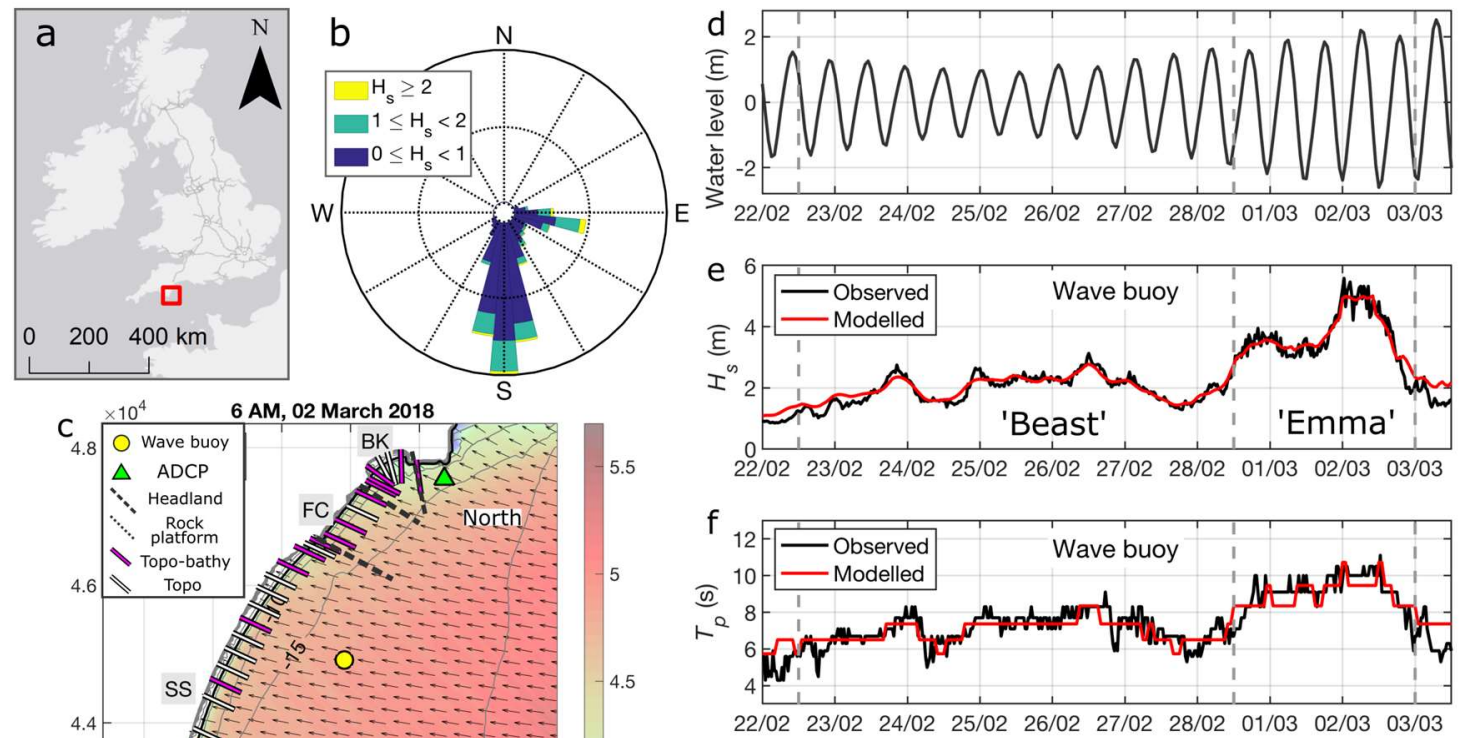

$\mathrm{g}$
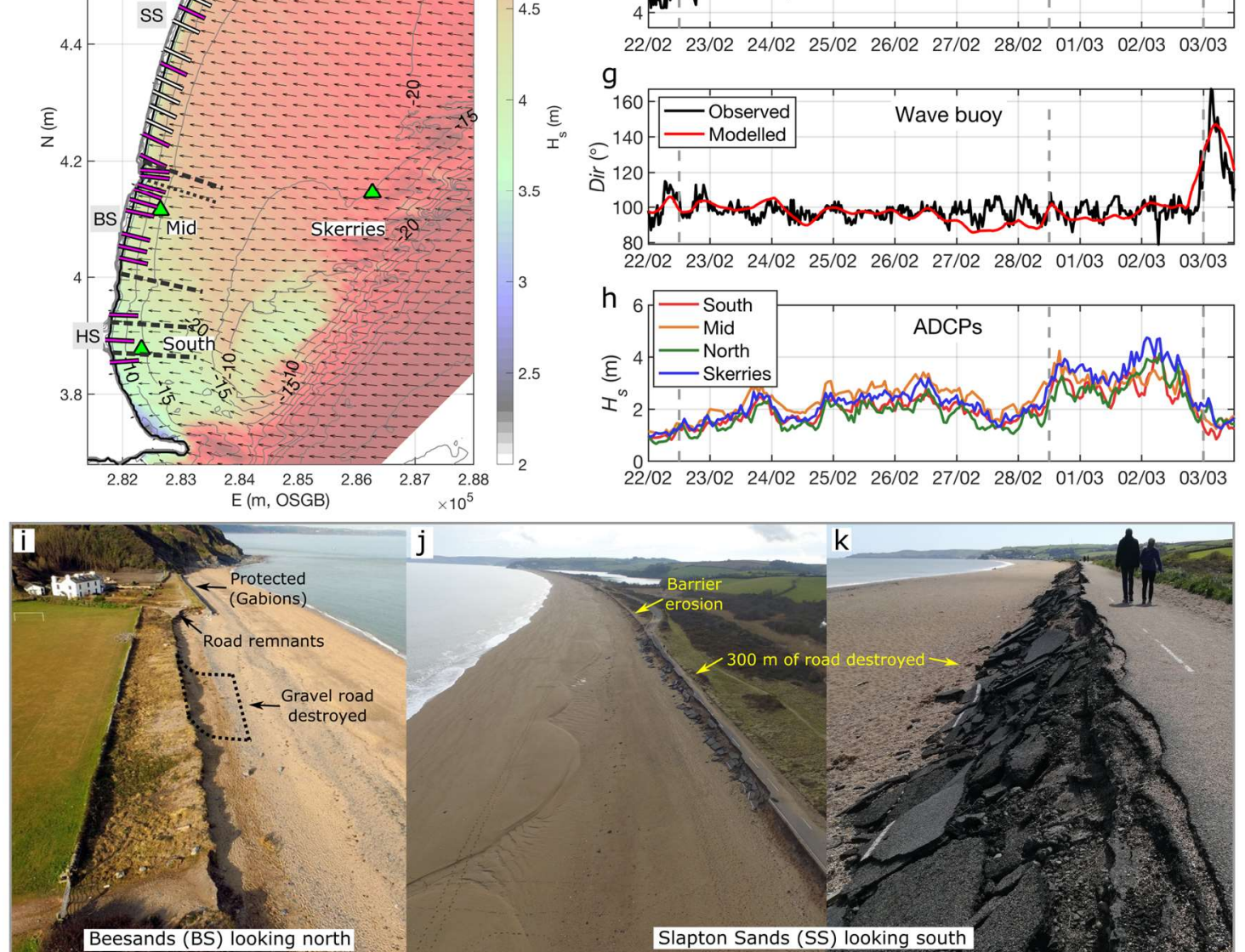

Figure 1. Start Bay site, including: (a) regional map; (b) wave rose for wave buoy data 2007-2018; (c) Start Bay with survey profiles, wave observation locations and synoptic modelled wave field during the storm peak [HSHallsands; BS-Beesands; SS-Slapton Sands; FC-Forest Cove; BK-Blackpool Sands]; (d) water level relative to mean from Skerries ADCP; (e) wave height at buoy; (f) peak period at buoy; (g) wave direction at buoy; (h) wave height at ADCPs; and (i-k) damage inflicted by Storm Emma. Photos: P. Ganderton. 


\section{Methods}

\subsection{Field observations}

A field experiment was conducted during Feb-Mar 2018 measuring hydrodynamic conditions and morphologic change across the beaches of Start Bay. Directional wave statistics and water levels were collected at 30-min intervals by four Acoustic Doppler Current Profilers (ADCPs), deployed in $14 \mathrm{~m}$ water depth (ODN) and a directional wave buoy deployed in 2007 by the Channel Coastal Observatory (CCO) at $-16 \mathrm{~m}$ ODN (Fig. 1c).

An extended easterly storm sequence occurred from $12 \mathrm{pm} 22^{\text {rd }}$ February to 12 am $3^{\text {nd }}$ March 2018 (Fig. 1e), comprised of two distinct phases: (i) a 6.5-day period [22-28/2/2018] described as 'The Beast From the East' by UK news outlets [herein referred to as 'Beast'], with mean $H_{s}=2.0 \mathrm{~m}, T_{p}=7.0 \mathrm{~s}$ and

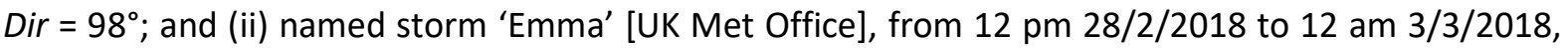
with mean $H_{s}=3.7 \mathrm{~m}, T_{p}=9.1 \mathrm{~s}$ and $\operatorname{Dir}=99^{\circ}$. Wave height peaked at $5.6 \mathrm{~m}$ at the wave buoy (Fig. $1 \mathrm{e}$ ) which is the maximum height since the buoy was deployed in 2007. This is estimated as at least a 1in-50 year event by extreme value analysis. 'Emma' was extremely destructive, washing away the road at both Beesands (BS, Fig. 1i) and Slapton Sands (SS, Fig. 1j-k), with extensive overwashing and localised flooding, and damage to coastal protection structures.

Fourty-four topographic profiles were measured along the extent of the embayment (Fig. 1c), together with 28 bathymetric profiles to -12 m ODN (Fig. 1c-pink lines). Topographic profiles were measured using a Real Time Kinematic Global Positioning System (RTK-GPS) device mounted to a walked surveying pole, with a $2 \sigma$-measurement error of $<0.05 \mathrm{~m}$ (Wiggins et al., 2019). Bathymetric surveys were conducted using a single beam echosounder synchronised with RTK-GPS at $1 \mathrm{~Hz}$, polemounted to an inflatable vessel, with $2 \sigma$-measurement error on the order of $0.14 \mathrm{~m}$ (Valiente et al., 2019).

All topo-bathymetric survey lines (pink lines, Fig. 1c) were surveyed 2-3 days prior to the start of the event sequence and all post-storm surveys were completed within 4 days of the end of the event. The remaining pre-storm topographic only profiles (white lines, Fig. 1c) were all surveyed within the month preceding the event, when minimal change occurred (average $\Delta V<3 \mathrm{~m}^{3} \mathrm{~m}^{-1}$, from 31/1/2018 to $20 / 2 / 2018$, along the centre of the SS embayment). Additional topography-only profiles were measured on a staggered schedule during the storm sequence, with the aim to cover a set of priority lines (pink lines, Fig. 1c) every 3 to 4 days.

\subsection{Wave transformation and alongshore wave power}

A SWAN wave model (Booij et al., 1999) was used to transform waves from offshore to the breakpoint, employing a $25-\mathrm{m}$ grid covering the extent of Start Bay. The model performed well in comparison to observations at the inner wave buoy and ADCPs (detail on model setup and skill in Supplementary Material 1). The wave buoy offshore of SS (Fig. 1c) is critical for later calculations of alongshore wave power and transport rates along SS, and at this location the model performed extremely well for wave height and period $\left(R_{H S}^{2}=0.96, R_{T p}^{2}=0.75\right)$. Wave direction was also well modelled, with low mean absolute error $\left(M A E_{d r n}=4.4^{\circ}\right)$ and low bias $\left(\right.$ Bias $\left._{d r n}=-1.2^{\circ}\right)$.

Alongshore wave power $\left(P_{y}\left[N s^{-1}\right]\right)$ was calculated using linear wave theory as:

$$
P_{y}=\frac{\rho g^{1.5}}{16 \sqrt{\gamma_{b}}} H_{b}^{2.5} \sin \left(2 \theta_{b}\right)
$$

Eq. 1

where $H_{b}$ is significant breaking wave height and $\theta_{b}$ is the breaking wave angle relative to the shoreline. A variable breakpoint was extracted directly from the wave model (details in Supplementary 
Material 1), using a conservative estimate (Van Rijn, 2014) of the irregular breaker index $\gamma_{b}=0.7 \pm$ 0.1 (i.e., a lower $\gamma_{b}$ equates to less refraction, higher alongshore power, and a lower transport coefficient). For comparison and replication purposes, we also applied the shoaling-refraction method of Van Rijn et al. (2014) to estimate a transport coefficient, noting this method is less robust, but much simpler. Shoreline angles were taken at the $-5 \mathrm{~m}$ ODN contour, representing the approximate average breakpoint over the storm sequence, extracted from a mid-2017 full-embayment topo-bathymetry (Wiggins et al., 2019). The analysis was also performed extracting the low-tide shoreline from aerial imagery, producing virtually identical results (not shown).

\subsection{Sediment volume and flux analysis}

Profile volumes were calculated for total, subtidal and sub-aerial (i.e., intertidal to supratidal) components, with the subtidal defined as $<-2 \mathrm{~m} O D N$, and a rotation correction applied to profiles not aligned to shore-normal. Total volumes were calculated by alongshore block-integration of profile cross-sectional areas, with a correction factor and uncertainty estimate based on development of an algorithm to convert between 2D profiles and 3D volumes (method described in Supplementary Material 2), using full-embayment topo-bathymetric 3D survey data (Wiggins et al., 2019). Additionally, measurement error $( \pm 0.1 \mathrm{~m})$ was incorporated into volumetric change calculations. For profiles where only the topography was surveyed (Fig. 1c, white lines), sub-tidal volumetric change was interpolated linearly alongshore between bathymetric profiles (Fig. 1c, pink lines).

Wiggins et al. (2019) demonstrated that the Start Bay sediment budget is closed, resolving all regions of erosion and accretion, across multiple epochs, and finding zero significant net change. Additionally, it is evident that an extended sub-aerial to subtidal region of bare rock exists at the northern limit of the embayment (northeast of BK; Fig. 1c), with no available sediment. Based on these factors, it is a reasonable assumption that flux through the northeast boundary profile is equal to zero, and that south-westerly transport, during an easterly event, can be calculated from alongshore volume change based on mass conservation. Observed flux rates $(Q)$ for each profile sector were determined by a cumulative sum of the corrected volume change $(\Delta V)$, from northeast to southwest, due to the uniform easterly wave direction. Cumulative alongshore flux uncertainty $(\delta Q)$, accounting for measurement error and 2D-to-3D conversion $(\delta V)$, was calculated as:

$$
\delta Q_{\text {profile }}(n)=\sqrt{\sum_{i=1}^{n} \delta V_{\text {profile }}^{2}(i)}
$$

Eq. 2

\subsection{Longshore transport formulations}

The 'CERC' alongshore transport equation (USACE, 2002), uses the 'energy flux' approach to relate alongshore volume flux to alongshore wave power:

$$
Q\left(m^{3} s^{-1}\right)=\frac{1}{\left(\rho_{s}-\rho\right) g(1-p)} K P_{y}
$$

where $\rho_{s}$ is sediment density $\left(2650 \mathrm{~kg} \mathrm{~m}^{3}\right), \rho$ is sea-water density $\left(1025 \mathrm{~kg} \mathrm{~m}^{3}\right), g$ is gravity, $p$ is sediment void-space $(0.4$, Chadwick et al., 2005), and $K$ is a proportionality coefficient. Note that $K$ values using $H_{r m s}$ are approximately double those for $H_{s}$, and we use $H_{s}$ throughout. A typical value of $K$ for sandy sediment is $\sim 0.39$ (USACE, 2002) when $H_{s}$ is used for the calculations, while a $K$-value for

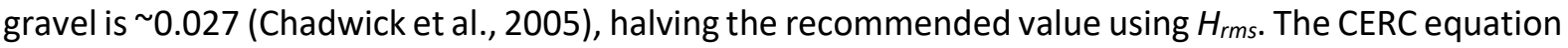
does not account for grain size, though several authors have noted that $K$ decreases for coarser sediment (Van Wellen et al., 2000). 
In addition to Eq. 3, we test the gravel-specific formula of Van Wellen et al. (2000) (herein VW2000; Eq. 4), and the generalised approach of Van Rijn (2014) (herein VR2014; Eq. 5). The VW2000 formula, which accounts for beach slope $(\tan \beta)$ and grain size $\left(D_{50}\right)$, was calibrated against the Shoreham UK observations (Chadwick, 1989) and validated against predictions of annual transport at Shoreham.

$$
Q_{V W}\left(m^{3} s^{-1}\right)=1.34 \frac{(1+p)}{\left(\rho_{s}-\rho\right)} H_{s b}^{2.49} T_{z}^{1.29}(\tan \beta)^{0.88} D_{50}^{-0.62}\left[\sin \left(2 \theta_{b}\right)\right]^{1.81}
$$

where $T_{z}$ is the zero-crossing period (taken as $T_{p} / 1.4$ ). VR2014 was calibrated against Chadwick (1989) and Nicholls and Wright (1991), as well as a range of sand-sized observations:

$$
Q_{V R}\left(m^{3} s^{-1}\right)=0.00018 K_{\text {swell }} g^{0.5}(\tan \beta)^{0.4} D_{50}^{-0.6} H_{s b}^{3.1} \sin \left(2 \theta_{b}\right) \quad \text { Eq. } 5
$$

$K_{\text {swell }}$ is a coefficient for the percentage of swell wave energy, varying from 1 (wind waves) to 1.5 (swell). We use $K_{\text {swell }}=1$ as wind waves were dominant throughout the observed event.

\section{Results}

Volumetric change, alongshore flux and wave power for the 8.5-day storm sequence are presented in Figure 2. Gross volumetric change was on the order of $700,000 \mathrm{~m}^{3}$ (Fig. 2b) with total net flux near zero, indicating the embayment is closed (within uncertainty bounds). An overall loss of $2.3 \pm 0.8 \times 10^{5}$ $\mathrm{m}^{3}$ was observed from the sub-aerial (Fig. 2c), balanced by an almost identical gain in the sub-tidal $\left(2.5 \pm 0.8 \times 10^{5} \mathrm{~m}^{3} ;\right.$ Fig. $\left.2 \mathrm{~d}\right)$. Exceptionally high rates of profile volume change were observed at the northern extent of the embayment (Fig. 2, third row) with erosion $\left(380 \mathrm{~m}^{3} \mathrm{~m}^{-1}\right)$ at SS19 (Fig. 2f), located immediately downdrift of a headland, and accretion $\left(400 \mathrm{~m}^{3} \mathrm{~m}^{-1}\right)$ at BK1, located updrift of a headland (Fig. 2d). Extreme change was observed in Forest Cove where multiple small embayments are interspersed with rock platforms and headlands, which limit sediment availability. At FC4 (Fig. 2g), 6 $\mathrm{m}$ of vertical erosion and a $60 \mathrm{~m}$ mean shoreline transgression resulted in the sub-aerial beach being completely eroded back to the cliff-face. Importantly, surveys taken within the 'Beast-Emma' storm sequence suggest that the great majority of volume change (>75\%) occurred within the later 'Emma' phase (Fig. 2e,g,h), implying that transport may be more efficient at higher energy levels.

Alongshore volume change (Fig. 2i) shows erosion downdrift and accumulation updrift of headlands, across multiple embayments (BS, SS, FC, BK), with more extreme values toward the north (right of Fig. 2a). At the centre of the longest embayment (SS), there is substantial accretion in the subtidal, which is partially offset by sub-aerial erosion. This indicates net offshore transport, overlain by dominant southward alongshore transport. Offshore transport (sub-tidal accretion) is also apparent near the middle of the BS embayment.

Total longshore flux $\left(Q, \mathrm{~m}^{3}\right)$ and total alongshore wave power $\left(P_{y}, \mathrm{~N}\right)$ are compared (Fig. 2j). Sediment flux uncertainty (blue envelope) increases southward but is reset to zero at the FC-BK headland, which is reasonable as there is confidence that no bypassing occurred at this headland ( $Q$ reduces to zero). A high correlation is apparent between $Q$ and $P_{y}$ along the middle SS embayment, away from the headlands (pink box, Fig. 2j), where sediment supply is unconstrained. Alongshore total flux peaks at $2 \times 10^{5} \mathrm{~m}^{3}$ toward the north of the SS embayment; this is comparable to net annual rates of transport (Wiggins et al., 2019; Chadwick et al., 2005), but is observed to occur here over a single event. Near headlands and within the smaller embayments, hard rock features act to restrict transport, such that $Q$ drops relative to $P_{y}$.

Taken as a whole (Fig. 2i,j), the dominant sediment transport pathways from north to south are: (i) rotation within BK, with no headland bypassing south into FC; (ii) erosion from FC, with substantial 
bypassing into SS; (iii) major erosion from north-SS (mostly sub-aerial), with deposition offshore of mid-SS; (iv) low rates of bypassing at BS-SS; (v) a peak in transport at the centre of BS that is proportional to wave energy; and (vi) a decrease in flux to zero south of $\mathrm{HS}$, where the shoreline angle becomes normal to the wave direction and Skerries Bank may provide some degree of sheltering to the coastline.
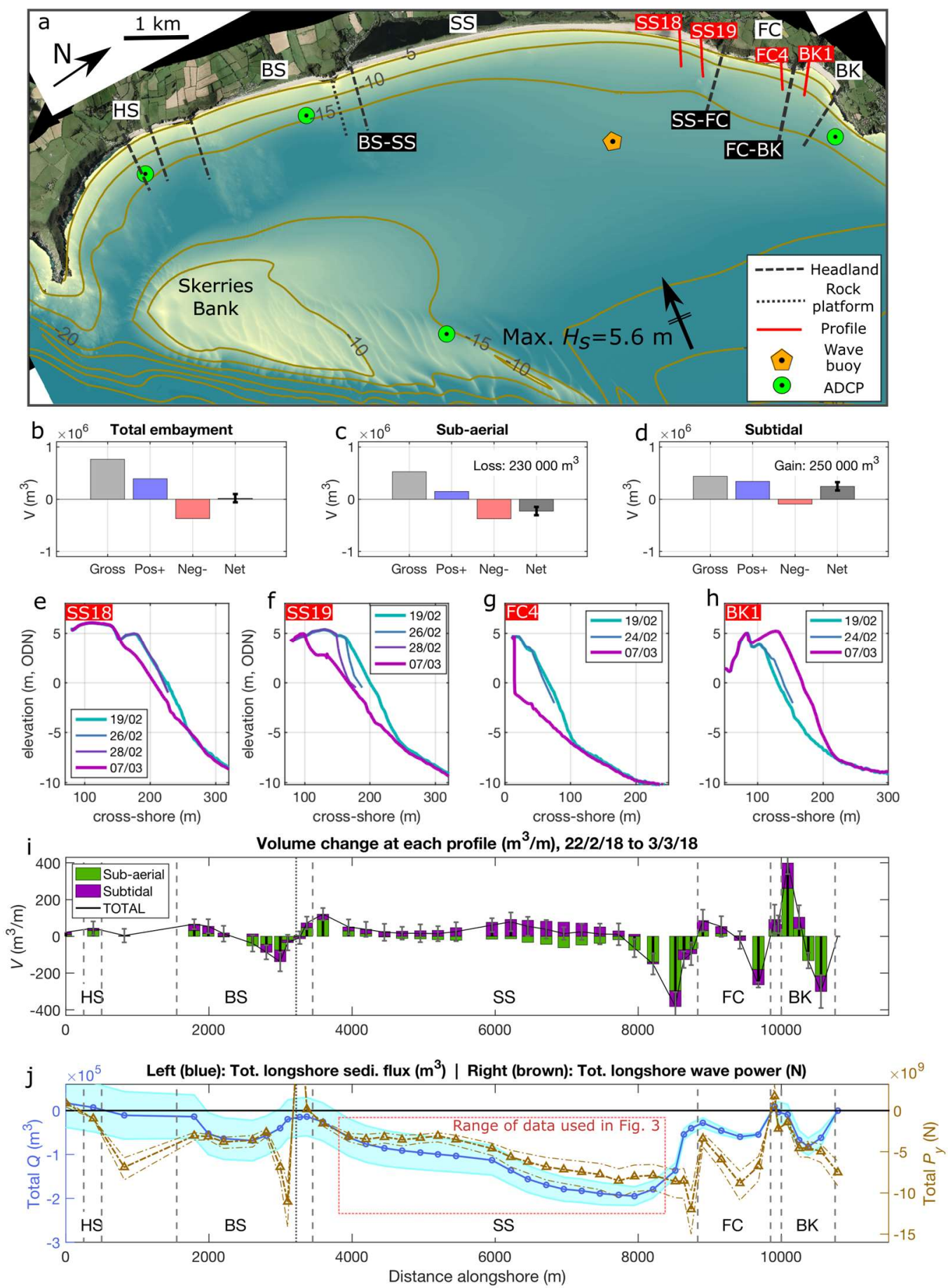

Figure 2. Morphologic change and wave power over the storm sequence. (a) Start Bay with selected profiles indicated; (b-d) total embayment volume change; (e-h) survey profile examples; (i) alongshore volume change for each profile sector, with error bars [ $[\delta \mathrm{V}$, Section 3.3]; and (j) cumulative alongshore sediment flux $[Q]$, error bounds (light blue) indicate maximum cumulative uncertainty [Eq. 4] and wave power $\left[P_{y}\right]$, with error bounds $\left[\gamma_{b}=0.7 \pm 0.1\right]$. For $(\mathrm{i}, \mathrm{j})$, headlands are indicated by grey dashed lines and shore-platform by grey dotted line. 


\section{Discussion}

\subsection{Unconstrained alongshore transport rates}

We now address our first objective, using $Q$ and $P_{y}$ to determine a transport rate coefficient for a section of open coast where flux is unimpeded by headlands and sediment supply (pink box, Fig. 2j). Total $Q$ and $P_{y}$ were found to be highly correlated in this region $\left(R^{2}=0.95\right)$, with a transport rate coefficient of $K=0.255$ (Fig. 3a), using $\gamma_{b}=0.7$ (Eq. 1). The uncertainty bounds for $K$ (grey dashed lines, Fig. 3a) are $K=0.2$ (for $\gamma_{b}=0.6$, lower bound) and $K=0.3$ (for $\gamma_{b}=0.8$, upper bound). In addition to the variable breakpoint method (Section 3.2), we applied the simplified approach for refraction and breaking given in Van Rijn (2014), also for a range of $\gamma_{b}=0.7 \pm 0.1$. This method produced marginally lower $P_{y}$ values, with lower sensitivity, such that all values plot within the optimal fit (Fig. 3a; $K=0.255$ ) and upper uncertainty bound $(K=0.3)$.

The derived $K$-value (0.255) is substantially higher than a standard rate for gravel transport (blue line, Fig. 3a; $K=0.027$; Chadwick et al., 2005), and is more than half the rate proposed for sand (red line, Fig. 3a; $K=0.39$; USACE, 2002). Transport predictions for VW2000 (Eq. 4) and VR2014 (Eq. 5) are also shown, using $D_{50}=5 \mathrm{~mm}$ (as per Chadwick et al., 2005) and $\tan \beta=0.125$. Both VW2000 and VR2014 are non-linear (in $P_{y}-Q$ parameter space) and a line of best-fit is shown. VR2014 underpredicts by a factor of 5 or more. VW2000 underpredicts by a factor of 2 to 5 .

Prior observations of gravel transport, digitised from Van Wellen et al. (2000) are plotted with observations from this study (Fig. 3b). Previous observations were in lower energy conditions $\left(P_{y}<\right.$ $3000 \mathrm{~N} / \mathrm{s})$, whilst all observations in this study are for $\left(P_{y}>3000 \mathrm{~N} / \mathrm{s}\right)$. Start Bay is comprised of fine gravel $\left(D_{50}=5 \mathrm{~mm}\right)$, whereas at Shoreham $D_{50}=20 \mathrm{~mm}$ (Bray et al, 1996; Chadwick, 1989), and $D_{50}=$ $30 \mathrm{~mm}$ at Hurst Castle (Nicholls and Wright, 1991); the latter coarse value potentially explains the low transport rates observed there. Our observations exhibit a similar $P_{y}-Q$ ratio to those of Bray et al., 1996 , and are consistent with a gravel transport rate $\sim 30 \%$ that of sand as determined by Van Wellen et al. (2000), though we note that a value this high is rarely cited in the literature.

Our results are also consistent with existing approaches that apply a variable $K$-value to gravel transport (Van Wellen et al., 2000), suggesting that transport becomes more efficient: (i) as energy increases; and/or (ii) above a given threshold. However, our observations imply a higher-efficiency rate of transport occurs under extreme conditions, beyond that captured by VW2000, which may be due to non-linear increases in suspended sediment transport at higher energy levels. Given the scant existing data (Fig. 3b), this study constitutes a substantial contribution to this poorly investigated area of research, increasing the parameter space of observations to be used in future formulations for gravel transport.

A previous estimate (Ruiz de Alegria-Arzaburu and Masselink, 2010) of sediment transport for the SS embayment (Fig. 2a) found a low transport rate $(K=0.05)$, using only topographic data. It is conclusive from our observations that a transport rate cannot be calculated for Start Bay without complete crossshore (topo-bathymetric) and alongshore (around headlands) coverage. For the mixed sand-gravel coastline of Playa Granada, Spain (Bergillos et al., 2017a,b), the VR2014 equation was found to accurately reproduce volumetric change, if the coarsest sediment fraction was used (as opposed to the $D_{50}$ ). This is the opposite result to the observations at Start Bay and may be related to the complexities of mixed sediment classes and nourishment at Playa Granada (Bergillos et al., 2017a,b).

The impact of the Beast-Emma event on Start Bay must also be put into the context of longer-term beach evolution. We observed an extreme event that produced a short burst of southward transport $\left(2 \times 10^{5} \mathrm{~m}^{3}\right)$, while the long-term trend is for northward transport. For example, $6 \times 10^{5} \mathrm{~m}^{3}$ was transported northward over a recent 3-year period dominated by southerly storms (2013 - 2016; Wiggins et al., 2019). This implies that an extreme event may be significant at an annual time-scale, 
with severe impacts on coastal infrastructure, but become less significant at the multi-annual to multidecadal time-scale, in the presence of a long-term trend.
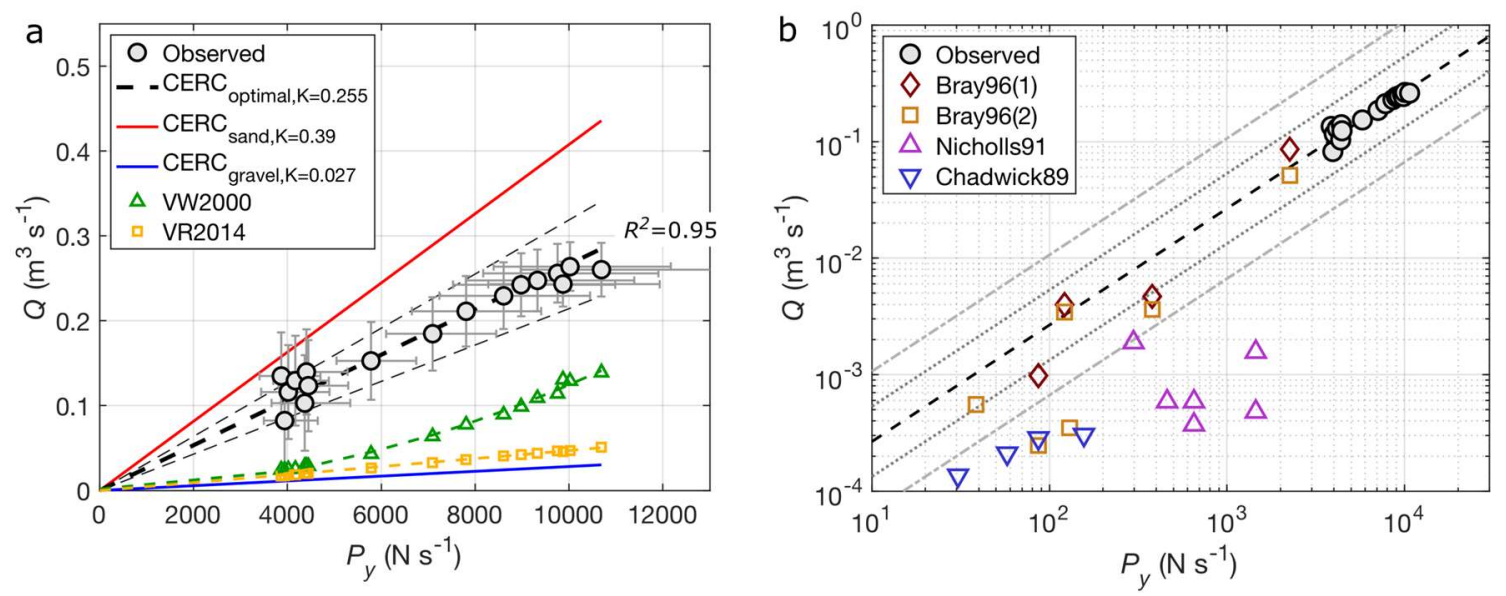

Figure 3. Comparison of alongshore transport formulations shown in $\left(P_{y}-Q\right)$ parameter space. (a) Observed data compared to previously proposed equations, VW2000 and VR2014 (green and yellow points), with lines-ofbest-fit added, CERC equation shown for sand $(K=0.39)$, gravel $(K=0.027)$ and an optimal value $(K=0.255)$ for the SS data from this study, error bars on observed values are as per Fig. $2 \mathrm{j}$, uncertainty bounds (grey dashed lines) are $\mathrm{K} \pm 0.05$. (b) Observations from this study ( $K=0.255$, identical to panel [a]), compared with Bray et al.

(1996), Nicholls and Wright (1991) and Chadwick (1989), on log-log axes, grey dotted and dash-dot lines represent variation of a factor of 2 and 4 respectively from $K=0.255$. Note: our observed values indicate varying alongshore positions, while other data points represent different wave events.

\subsection{Constrained transport and headland bypassing rates}

Our second objective was to examine transport rates in rocky areas and around headlands, where flux is impeded by physical barriers and limited by sediment supply. We take the transport rate established in the previous section $(K=0.255)$ and use this to determine predicted rates of flux (Eq. 3 ) along the embayment (Fig. 4a).

Embayments FC and BK display similar patterns of $Q_{o b s}$ and $Q_{\text {pred }}$ (Fig. 4a), with $Q_{\text {pred }}$ decreasing from north to south, while $Q_{o b s}$ peaks in the centre of the embayment, away from the headlands. The reversal in $Q_{\text {pred }}$ between BS and SS is due to a protruding rock platform. We further explain restrictions on transport by defining a headland bypass rate $(H B R)$ as a simple ratio of the observed rate of bypass $\left(Q_{\text {bypass,obs }}\right)$ over the predicted alongshore flux $\left(Q_{\text {up,pred }}\right)$, taken at the adjacent profile updrift of the headland, where transport is unconstrained.

$$
H B R=\frac{Q_{\text {bypass }, o b s}}{Q_{\text {up }, \text { pred }}}
$$

Morphometrics of each headland were evaluated from rectified aerial imagery, using five sets of images taken from 2012 to 2018. A 5-m contour (approx. back of beach) was extracted from an Oct 2017 image (pre-storm) at a distance of $100 \mathrm{~m}$ up- and down coast from the headland, then connected with a straight line (blue lines, Fig. $4 \mathrm{~b}$-d). Cross-shore extent was quantified for each of the five aerial images $(2012-2018)$ measuring offshore to the extent of exposed rock at the headland (orange lines, Fig. $4 b-d)$. The elevation at the offshore extent of this line was defined as the depth of the headland toe (toe-depth). Cross-shore extent and toe-depth vary over time due to erosion and accretion occurring around the headland. HBR was evaluated at three headlands (Fig. 4b-d; BS-SS, SS-FC, FC-BK).

The range of $H B R$ values varies from $\sim 0 \%$ (FC-BK, Fig. 4d) to 31\% (BS-SS, Fig. 4b). Bypass rates are controlled by variations in shoreline orientation and wave angle at two of the headlands, with a 
substantial decrease in $Q_{\text {pred }}$ around SS-FC and a reversal at FC-BK. This demonstrates that, even in the absence of knowledge of headland morphometry, changes in shoreline orientation adjacent to a headland may be sufficient to partially or entirely block transport.

Headland morphometry acts as an additional control, with the most 'permeable' headland (BS-SS) having the lowest extent ( 45 to $65 \mathrm{~m}$ ) and toe-depth ( 0 to $-3 \mathrm{~m}$ ODN), while the blocked headland (FCBK) has the greatest extent ( 95 to $110 \mathrm{~m}$ ) and toe-depth (-2 to $-7 \mathrm{~m}$ ). The middle headland (SS-FC, Fig. 4c) has an intermediate bypass rate (18\%), this is partly due to the updrift sediment supply blockage (at FC-BK). The observed trend is that larger, deeper headlands that are associated with greater change in the shoreline orientation force a decrease in $H B R$.

While it is relatively straightforward to predict bypassing rates around groynes and other nearidealised structures (e.g., Pelnard-Considere, 1956; Larson et al., 1997), it has proven far more difficult to predict bypassing around the complex morphology of natural headlands (George et al., 2015, 2019; Vieira da Silva et al., 2016, 2018; McCarroll et al., 2018), and no generalised formula exists for predicting headland bypass rates. Given the underdeveloped state of research in this area and the near absence of robust observations of headland bypassing rates, the measurements described here are of significant value. A larger sample is required to determine quantitative forcing relationships, which will require our observations to be combined with a numerical modelling approach.

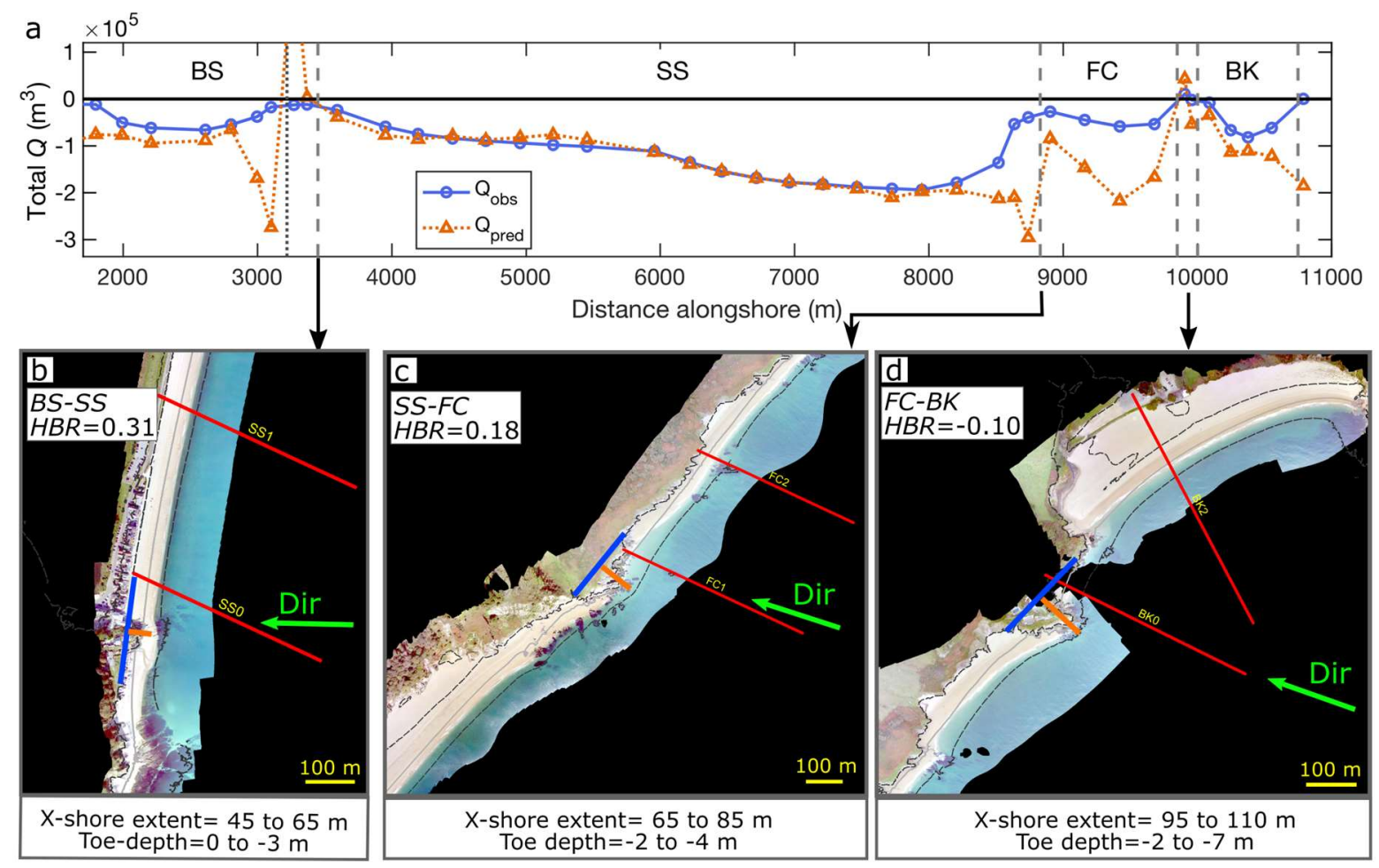

Figure 4. Headland bypassing rates for three headlands. (a) Observed and predicted alongshore flux at profiles updrift and at the headland. (b-d) Aerial images of each headland, with -5-m, 0-m and 5-m contours indicated, blue line joins 5 -m contour $\pm 100 \mathrm{~m}$ of the headland, orange line is approx. headland extent (varies over time with morphologic change), red lines are profile locations with wave direction at storm peak (green arrow). 
McCarroll et al. Author's version of ESPL article, published 29 June 2019.

\section{Conclusions}

Observations of gravel transport over an extreme event were reported, determining the sediment budget across multiple embayments divided by small headlands. Unprecedented levels of volume change were observed (up to $400 \mathrm{~m}^{3} \mathrm{~m}^{-1}$ ), with cumulative alongshore flux of $200000 \mathrm{~m}^{3}$, comparable to annual rates of net alongshore transport at this location. Longshore transport was characterised in terms of volume flux and alongshore wave power as being either constrained or unconstrained by headlands and sediment supply.

A stretch of open shoreline was used to determine a transport rate during extreme energy conditions (CERC equation, $K=0.255 \pm 0.05$ ), which is factor of 5 or more greater than values determined under lower energy conditions. Accordingly, future transport formulations for gravel may need to account for greater transport potential during high energy conditions by applying a variable rate or thresholdbased approach. Areas where transport was constrained by headlands were analysed, for the first time providing headland bypass rates in terms of observed and predicted rates of alongshore sediment flux. Bypass rates ranged from $\sim \%$ to $31 \%$, decreasing for larger headlands, but also due to changes in shoreline orientation that act to reduce alongshore wave power. Future efforts will use this dataset to calibrate a range of modelling approaches applied to gravel embayments.

\section{ACKNOWLEDGMENTS}

This work was funded by UK Natural Environment Research Council grant (NE/M004996/1; BLUE-coast project). All authors contributed significantly to the planning and execution of field work, and to research design. GM and TS provided editorial support on the manuscript. Our thanks to the many people who helped collect these data, including: Peter Ganderton, Aaron Barrett, Tim Poate, Erin King and Olivier Burvingt. Thanks for additional data provided by the Channel Coastal Observatory, Met Office and UKHO. Data from this study are available from the University of Plymouth PEARL data repository (https://doi.org/10.24382/c3ee-6p96).

\section{REFERENCE LIST}

Bergillos, R. J., Masselink, G., \& Ortega-Sánchez, M. (2017). Coupling cross-shore and longshore sediment transport to model storm response along a mixed sand-gravel coast under varying wave directions. Coastal Engineering, 129, 93-104.

Bergillos, R. J., Rodríguez-delgado, C., \& Ortega-sánchez, M. (2017). Advances in management tools for modeling artificial nourishments in mixed beaches. Journal of Marine Systems, 172, 1-13. https://doi.org/10.1016/j.jmarsys.2017.02.009

Booij, N., Ris, R. C., \& Holthuijsen, L. H. (1999). A third-generation wave model for coastal regions: 1. Model description and validation. Journal of Geophysical Research, 104(C4), 7649-7666. https://doi.org/10.1029/98JC02622

Bray, M. J., Workman, M., Smith, J., \& Pope, D. (1996). Field measurements of shingle transport using electronic tracers. In: Proceedings of the 31st MAFF Conference of River and Coastal Engineers. Loughborough, UK (Vol. 10, pp. 1-10).

Buscombe, D., \& Masselink, G. (2006). Concepts in gravel beach dynamics. Earth-Science Reviews, 79(1-2), 33-52.

Chadwick, A. J. (1989). Field measurements and numerical model verification of coastal shingle transport. Advances in Water Modelling and Measurement, 381-402.

Chadwick, A. J., Karunarathna, H., Gehrels, W. R., Massey, A. C., O'Brien, D., \& Dales, D. (2005). A new analysis of the Slapton barrier beach system, UK. In: Proceedings of the Institution of Civil Engineers-Maritime Engineering (Vol. 158, pp. 147-161). Thomas Telford Ltd. 
George, D. A., Largier, J. L., Storlazzi, C. D., \& Barnard, P. L. (2015). Classification of rocky headlands in California with relevance to littoral cell boundary delineation. Marine Geology, 369, 137-152. https://doi.org/10.1016/j.margeo.2015.08.010

George, D. A., Largier, J. L., Pasternack, G. B., Barnard, P. L., Storlazzi, C. D., \& Erikson, L. H. (2019). Modeling sediment bypassing around idealized rocky headlands. Journal of Marine Science and Engineering, 7(2), 40.

Goodwin, I. D., Freeman, R., \& Blackmore, K. (2013). An insight into headland sand bypassing and wave climate variability from shoreface bathymetric change at Byron Bay, New South Wales, Australia. Marine Geology, 341, 29-45. https://doi.org/10.1016/j.margeo.2013.05.005

Hails, J. R. (1975). Submarine geology, sediment distribution and Quaternary history of Start Bay, Devon. Journal of the Geological Society, 131(1), 1-5.

Harley, M. D., Turner, I. L., Short, A. D., \& Ranasinghe, R. (2011). Assessment and integration of conventional, RTK-GPS and image-derived beach survey methods for daily to decadal coastal monitoring. Coastal Engineering, 58(2), 194-205. https://doi.org/10.1016/j.coastaleng.2010.09.006

Larson, M.; Hanson, H.; Kraus, N. C. Analytical solutions of one-line model for shoreline change near coastal structures. J. Waterw. Port, Coastal, Ocean Eng. 1997, 123, 180-191.

Luijendijk, A. P., Ranasinghe, R., de Schipper, M. A., Huisman, B. A., Swinkels, C. M., Walstra, D. J., \& Stive, M. J. (2017). The initial morphological response of the Sand Engine: A process-based modelling study. Coastal engineering, 119, 1-14.

Masselink, G., Russell, P., Blenkinsopp, C., \& Turner, I. (2010). Swash zone sediment transport , step dynamics and morphological response on a gravel beach. Marine Geology, 274(1-4), 50-68. https://doi.org/10.1016/j.margeo.2010.03.005

Masselink, G., Scott, T., Poate, T., Russell, P., Davidson, M., \& Conley, D. (2016). The extreme 2013/2014 winter storms: hydrodynamic forcing and coastal response along the southwest coast of England. Earth Surface Processes and Landforms, 41(3), 378-391.

McCall, R. T., Masselink, G., Poate, T. G., Roelvink, J. A., Almeida, L. P., Davidson, M., \& Russell, P. E. (2014). Modelling storm hydrodynamics on gravel beaches with XBeach-G. Coastal Engineering, 91, 231-250. https://doi.org/10.1016/j.coastaleng.2014.06.007

McCarroll, R., Masselink, G., Valiente, N., Scott, T., King, E., \& Conley, D. (2018). Wave and Tidal Controls on Embayment Circulation and Headland Bypassing for an Exposed, Macrotidal Site. Journal of Marine Science and Engineering, 6(3), 94. https://doi.org/10.3390/jmse6030094.

Nicholls, R. J., \& Wright, P. (1991). Longshore transport of pebbles: experimental estimates of K. In: Coastal Sediments (pp. 920-933). ASCE.

Pelnard-Considere, R. Essai de theorie de l'evolution des formes de rivage en plages de sable et de galets. Les Energies la Mer Compte Rendu Des Quatr. Journees L'hydraulique, Paris 13, 1415 Juin 1956; Quest. III, Rapp. 1, 74-1-10 1956.

Ruiz de Alegria-Arzaburu, A., \& Masselink, G. (2010). Storm response and beach rotation on a gravel beach, Slapton Sands, U.K. Marine Geology, 278(1-4), 77-99. https://doi.org/10.1016/j.margeo.2010.09.004

Schoonees, J. S., \& Theron, A. K. (1993). Review of the field-data base for longshore sediment transport.

Scott, T., Masselink, G., O'Hare, T., Saulter, A., Poate, T., Russell, P., Davidson, M., \& Conley, D. (2016). The extreme 2013/2014 winter storms: Beach recovery along the southwest coast of England. Marine Geology, 382, 224-241. https://doi.org/10.1016/j.margeo.2016.10.011

Tomasicchio, G. R., Alessandro, F. D., Barbaro, G., \& Malara, G. (2013). General longshore transport model. Coastal Engineering, 71, 28-36. https://doi.org/10.1016/j.coastaleng.2012.07.004 
USACE. (2002). Shore Protection Manual. Coastal Engineering Research Center, Government Printing Office,Washington DC.

Valiente, N. G., Masselink, G., Scott, T., Conley, D., \& McCarroll, R. J. (2019). Role of waves and tides on depth of closure and potential for headland bypassing. Marine Geology, 407, 60-75.

Van Rijn, L. C. (2011). Coastal erosion and control. Ocean \& Coastal Management, 54(12), 867-887.

Van Rijn, L. C. (2014). A simple general expression for longshore transport of sand, gravel and shingle. Coastal Engineering, 90, 23-39. https://doi.org/10.1016/j.coastaleng.2014.04.008

Van Wellen, E., Chadwick, A. J., \& Mason, T. (2000). A review and assessment of longshore sediment transport equations for coarse-grained beaches. Coastal Engineering, 40(3), 243-275.

Vieira da Silva, G., Toldo, E. E., Klein, A. H. d. F., Short, A. D., \& Woodroffe, C. D. (2016). Headland sand bypassing - Quantification of net sediment transport in embayed beaches, Santa Catarina Island North Shore, Southern Brazil. Marine Geology, 379, 13-27. https://doi.org/10.1016/j.margeo.2016.05.008

Vieira da Silva, G. V., Toldo Jr, E. E., Klein, A. H. D. F., \& Short, A. D. (2018). The influence of wave-, wind-and tide-forced currents on headland sand bypassing-Study case: Santa Catarina Island north shore, Brazil. Geomorphology, 312, 1-11.

Wiggins, M., Scott, T., Masselink, G., Russell, P., \& McCarroll, J. (2019). Coastal embayment rotation: Response to extreme events and climate control, using full embayment surveys. Geomorphology. https://doi.org/10.1016/j.geomorph.2018.11.014.

Woodroffe, C. D., Cowell, P. J., Callaghan, D. P., Ranasinghe, R., Jongejan, R., Wainwright, D. J., Barry, S.J., Rogers, K., \& Dougherty, A. J. (2012). Approaches to risk assessment on Australian coasts: A model framework for assessing risk and adaptation to climate change on Australian coasts. National Climate Change Adaptation Research Facility, Gold Coast, 205 pp. 


\section{Supplementary Material 1:}

\section{Wave transformation model skill and breakpoint value extraction}

A SWAN wave transformation model (Booij et al., 1999), packaged within the Delft3D modelling suite as Delft3D-WAVE, was used to transform waves from offshore to the breakpoint, employing an outer $250 \mathrm{~m}$ by $250 \mathrm{~m}$ grid and inner $25 \mathrm{~m}$ by $25 \mathrm{~m}$ grid that covered the extent of Start Bay. Bathymetry for the wave model was obtained from a 2017 full-embayment survey of the Start Bay shoreline and nearshore (Wiggins et al., 2019), merged with nearshore to offshore mulitbeam bathymetric data from the United Kingdom Hydrographic Office (2013). The model was forced with parametric wave values outputted from a regional 8-km grid Wave Watch III (WWIII) model produced by the UK Met Office, and by water levels from the Forecasting Ocean Assimilation Model, 7-km Atlantic Margin Model (FOAM-AMM7), with a $+0.39 \mathrm{~m}$ offset applied to water level to account for sea level rise in southwest UK since the introduction of Ordnance Data Newlyn (ODN). Wind strength values, for forcing wave generation within the model domain, were obtained from the IFREMER CERSAT Global Blended Mean Wind Fields observations ( $0.25^{\circ}$ resolution). The Met Office WWIII wave model data, FOAM-AMM7 water level and flow model data, and IFREMER CERSET Global wind observations are all available from the Copernicus Marine Environment Monitoring Service (CMEMS; marine.copernicus.eu).

Our model, using boundary input from the Met Office model, was found to underpredict wave height at the peak of the storm and therefore a manual correction factor of up to 1.3 was applied to the boundary wave height for 12 hours over the peak of the storm. For peak wave period $\left(T_{p}\right)$, model skill was improved by taking the mean absolute zero-crossing period $\left(T_{m 02}\right)$ from the Met Office WWIII model, multiplied by a factor of 1.6, and using this as the boundary condition for $T_{p}$. Directional spreading was set to a uniform value of $30^{\circ}$. Refraction was included in the model. The wave breaking parameter for the SWAN model was set to $0.8\left(\gamma_{b}=H_{b} / h_{b}\right.$; where, at the breakpoint, $H_{b}$ is significant wave height and $h_{b}$ is depth); however, we later extract a range a variable breakpoints from the model output to determine alongshore wave power, which accounts for uncertainty in the location of the breakpoint. Other settings were as per default values. Model skill values are given in Table S1-1.

Table S1-1. Wave transformation model skill

\begin{tabular}{cc|c|cccc} 
& & \multicolumn{5}{c}{ ADCP } \\
Variable & Metric & Wave buoy & South & Mid & North & Skerries \\
\hline \multirow{2}{*}{$H_{s}(\mathrm{~m})$} & $R^{2}$ & 0.96 & 0.87 & 0.66 & 0.86 & 0.91 \\
& MAE & 0.17 & 0.21 & 0.39 & 0.24 & 0.21 \\
& Bias & 0.04 & 0.13 & -0.14 & 0.15 & 0.11 \\
& & & & & & \\
$T_{p}(\mathrm{~s})$ & $R^{2}$ & 0.75 & 0.65 & 0.56 & 0.72 & 0.67 \\
& MAE & 0.56 & 0.61 & 0.64 & 0.51 & 0.56 \\
& Bias & -0.03 & 0.23 & 0.34 & 0.17 & 0.15 \\
& & & & & & \\
$\operatorname{Dir}($ deg.) & $R^{2}$ & 0.22 & 0.17 & 0 & 0.34 & 0.23 \\
& MAE & 4.37 & 5.04 & 9.05 & 5.67 & 5.98 \\
& Bias & -1.11 & -1.92 & -6.70 & 5.46 & 0.10
\end{tabular}

MAE - Mean absolute error. Wave buoy and ADCP positions provided in primary manuscript, Fig. $1 \mathrm{c}$. 
A temporal and spatially varying breakpoint (Fig. S1-1) was extracted at each survey profile using the following algorithm:

1. The SWAN model was run with a fixed value of $\gamma_{b}=0.8$.

2. An 'offshore' wave height $\left(H_{0}\right)$ was extracted from the SWAN model, taking a value $400 \mathrm{~m}$ offshore of the start of the line, which is typically at $12 \mathrm{~m}$ water depth. This value was selected as being clearly beyond the breakpoint even at the peak of the storm sequence.

3. $\gamma=H_{0} / h$ was calculated at each point moving offshore, at $5 \mathrm{~m}$ intervals, interpolated from the $25 \mathrm{~m} \times 25 \mathrm{~m}$ wave model grid.

4. The breakpoint was determined as first point at which $\gamma<\gamma_{b}$. An additional $10 \mathrm{~m}$ was added to this value to account for occcasional anomalous values occuring in small waves where depth changes rapidly relative to the grid size.

5. $\gamma_{b}$ was calculated for $0.7 \pm 0.1$.
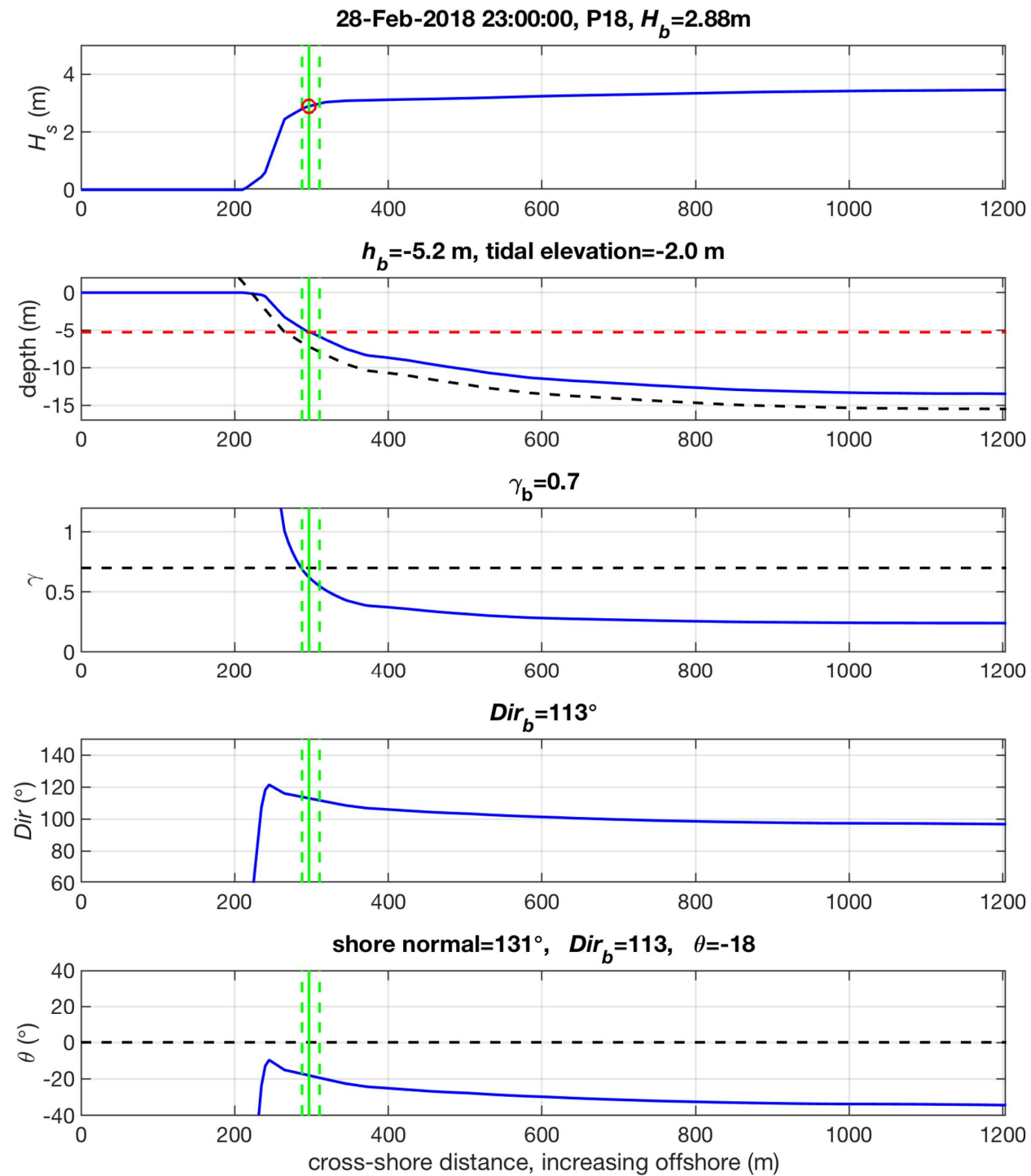

Figure S1-1. Variable break point extraction, including: (top row) Hs; (second row) depth, blue line is depth accounting for tide, black dashed line is bed level [m, ODN], red dashed line is variable breaking depth for this time point; (third row) $\gamma=H_{0} / h$, black dashed line is $\gamma=0.7$; (fourth row) direction; and (bottom row) direction relative to shore normal. Green vertical lines indicate $\gamma_{b}=0.7 \pm 0.1$ across all variables, note the $10 \mathrm{~m}$ offshore offset of $\gamma_{b}$ (step 4 in the above algorithm). 
For replication purposes, note that we intially performed the full analysis by extracting wave values $\left(H_{b}, \theta_{b}\right)$ at a fixed point on each profile at the 8-m depth contour, using $\gamma_{b}=0.72$. This approach produced similar results to the variable-breakpoint method presented in the main document (on open sections of beach), with a slightly lower transport coefficient $(K=0.22)$ due to refraction occuring onshore of the 8-m depth contour being unaccounted for. There is no common method in the literature for dealing with wave transformation and alongshore wave power; however, our approach will give similar results to the simplified approach of Van Rijn (2014). We found the Van Rijn (2014) method provided a slightly lower estimate of wave power (0 to 20\%) and therefore a higher $K$-value. For reference, we applied Van Rijn (2014) Eq. 12 (using $\alpha=0.18$ ) and Eq. 13 (determining an intermediate wave celerity using the dispersion relation).

\section{Supplementary Material 2: Converting 2D-profiles to 3D-volumes}

Uncertainty estimates for volumetric change were determined using an algorithm to convert from 2Dprofiles to 3D-volumes using existing fully-3D digital elevation models (DEMs) (Wiggins et al., 2019) from Start Bay taken in 2016, 2017 and 2018. Profiles were extracted from high resolution (1-m gridded) 3D survey data, then multiplied by the alongshore distance to the mid-points between profiles (Fig. S2-1), this was then compared against volumes directly calculated from the 3D-DEM data for the three survey years (2016 to 2018). Volumes calculated from the 3D-DEMs were taken between a lower elevation limit of $-10 \mathrm{~m}$ ODN (approx. depth of closure) and an upper limit of $6 \mathrm{~m}$ ODN (approx. upper limit of beach). 3D volumes were calculated from a 5-m grid DEM.

A correction factor (Table S2-1) was then applied based on the mean difference between 2D- and 3D estimates of beach volume, this adjustment accounts for shoreline curvature and rocky areas interspersed with small bays (Fig. S2-1). After applying the correction, volumetric change for three epochs was calculated (2016-2017, 2017-2018, 2016-2018) and uncertainty at each profile was determined as the maximum difference between volumetric change estimates between the 2D and 3D methods (Error, Table S2-1). We use maximum difference rather than standard deviation as a more conservative option, to avoid underestimating the uncertainty, given the small number of sample points.

For areas with small coves and cliffs, a correction factor of significantly $<1$ occurs where the profile is taken in the middle of a pocket embayment, thus overestimating the overall volume in the region. For example profile FC4 (Fig. S2-1) is at the centre of a small embayment, but is bordered by headlands, cliffs and rock outcrops. As a result, FC4 has a correction factor of 0.72 . By comparison, profiles along Slapton Sands have multipliers $\approx 1$, indicating that simple block extrapolation of the profile is a good estimate of volume along long open stretches of beach. 
McCarroll et al. Author's version of ESPL article, published 29 June 2019.

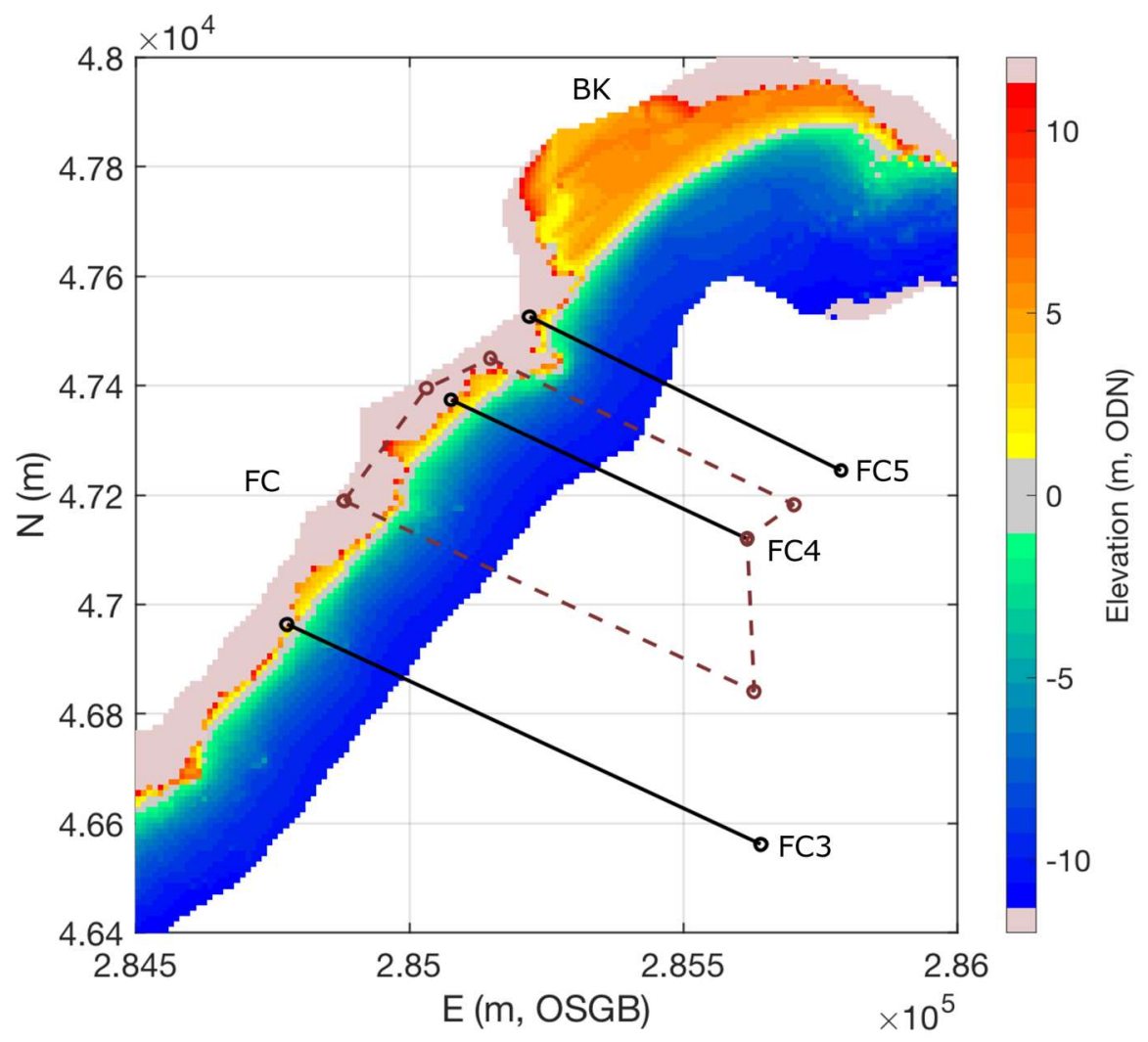

Figure S2-1. 2D-to-3D profile to volume conversion. Colour grid is a 2018 3D digital elevation model. Black line FC4 is the profile being extrapolated from 2D to 3D. Dashed brown lines indicate the mid-points between profiles. The $2 \mathrm{D}$ profile is multiplied by the distance between up- and down-coast midpoints. A correction is then applied based on the difference between 2D and 3D estimates of volume. 
McCarroll et al. Author's version of ESPL article, published 29 June 2019.

Table S2-1: Conversion from 2D to 3D volumes

\begin{tabular}{|c|c|c|c|c|c|}
\hline Profile ID & $\begin{array}{l}\text { Correction } \\
\text { Factor }\end{array}$ & $\operatorname{Error}\left(m^{3} / m\right)$ & Profile ID & $\begin{array}{l}\text { Correction } \\
\text { Factor }\end{array}$ & $\begin{array}{l}\text { Error } \\
\left(\mathrm{m}^{3} / \mathrm{m}\right)\end{array}$ \\
\hline HS1 & 0.98 & 21.08 & SS11 & 0.99 & 19.40 \\
\hline HS2 & 0.88 & 19.57 & SS12 & 1.01 & 18.01 \\
\hline$B S 1$ & 0.73 & 6.37 & SS13 & 1.01 & 2.06 \\
\hline$B S 2$ & 0.97 & 9.58 & SS14 & 0.95 & 11.85 \\
\hline$B S 3$ & 1.00 & 6.88 & SS15 & 1.03 & 24.68 \\
\hline BS5 & 1.00 & 25.00 & SS16 & 1.01 & 24.49 \\
\hline BS6 & 0.97 & 3.82 & SS17 & 1.00 & 6.77 \\
\hline BS7 & 0.95 & 19.62 & SS18 & 1.03 & 7.92 \\
\hline BS8 & 0.97 & 11.72 & SS19 & 1.04 & 39.12 \\
\hline BS9 & 0.95 & 16.49 & SS2O & 0.99 & 13.22 \\
\hline$B S 10$ & 0.92 & 15.15 & SS21 & 1.06 & 35.42 \\
\hline SSO & 1.06 & 14.61 & $F C 1$ & 0.74 & 36.97 \\
\hline SS1 & 0.94 & 20.79 & $F C 2$ & 0.66 & 27.73 \\
\hline SS2 & 0.99 & 17.47 & $F C 3$ & 1.03 & 11.62 \\
\hline SS3 & 0.97 & 20.62 & $F C 4$ & 0.72 & 4.15 \\
\hline SS4 & 0.99 & 6.84 & $F C 5$ & 1.00 & 46.78 \\
\hline SS5 & 1.00 & 18.11 & BKO & 0.65 & 18.99 \\
\hline SS6 & 0.96 & 10.28 & $B K 1$ & 1.03 & 28.80 \\
\hline SS7 & 1.01 & 20.17 & $B K 2$ & 0.96 & 31.56 \\
\hline SS9 & 1.02 & 4.77 & $B K 3$ & 0.98 & 11.17 \\
\hline SS10 & 0.94 & 17.25 & BK4 & 1.08 & 55.02 \\
\hline
\end{tabular}

Profiles are listed from south to north, prefixes indicate embayment names [HS-Hallsands; BS-Beesands; SSSlapton Sands; FC-Forest Cove; BK-Blackpool Sands]. See Figure 1 in main document for map of profile locations. The highlighted profile (FC4) is used as an example in Figure S2-1. 